\title{
BMJ Global Health Organisation of primary health care systems in low- and middle-income countries: review of evidence on what works and why in the Asia- Pacific region
}

\author{
Rebecca Dodd, ${ }^{\oplus 1}$ Anna Palagyi, ${ }^{\oplus}$ Stephen Jan, ${ }^{1,2}$ Marwa Abdel-All, ${ }^{\oplus 1}$ \\ Devaki Nambiar, ${ }^{3}$ Pavitra Madhira, ${ }^{3}$ Christine Balane, ${ }^{1}$ Maoyi Tian, ${ }^{4}$ \\ Rohina Joshi, ${ }^{1,2,3}$ Seye Abimbola, ${ }^{1,2}$ David Peiris ${ }^{\circledR 1}$
}

\begin{abstract}
To cite: Dodd R, Palagyi A, Jan $\mathrm{S}$, et al. Organisation of primary health care systems in low- and middleincome countries: review of evidence on what works and why in the Asia-Pacific region. BMJ Global Health 2019;4:e001487. doi:10.1136/ bmjgh-2019-001487
\end{abstract}

Handling editor Valery Ridde

- Additional material is published online only. To view please visit the journal online (http://dx.doi.org/10.1136/ bmjgh-2019-001487).

Received 8 February 2019 Revised 15 June 2019 Accepted 23 June 2019

Check for updates

(c) Author(s) (or their employer(s)) 2019. Re-use permitted under CC BY-NC. No commercial re-use. See rights and permissions. Published by BMJ.

For numbered affiliations see end of article.

Correspondence to

Dr Rebecca Dodd;

rdodd@georgeinstitute.org.au

\begin{abstract}
Introduction This paper synthesises evidence on the organisation of primary health care (PHC) service delivery in low-income and middle-income countries (LMICs) in the Asia Pacific and identifies evidence of effective approaches and pathways of impact in this region.

Methods We developed a conceptual framework describing key inputs and outcomes of PHC as the basis of a systematic review. We searched exclusively for intervention studies from LMICs of the Asia-Pacific region in an effort to identify 'what works' to improve the coverage, quality, efficiency, equity and responsiveness of PHC. We conducted a narrative synthesis to identify key characteristics of successful interventions.

Results From an initial list of 3001 articles, we selected 153 for full-text review and included 111. We found evidence on the impact of non-physician health workers (NPHWs) on coverage and quality of care, though better integration with other PHC services is needed. Communitybased services are most effective when well integrated through functional referral systems and supportive supervision arrangements, and have a reliable supply of medicines. Many studies point to the importance of community engagement in improving service demand. Few studies adopted a 'systems' lens or adequately considered long-term costs or implementation challenges.

Conclusion Based on our findings, we suggest five areas where more practical knowledge and guidance is needed to support PHC systems strengthening: (1) NPHW workforce development; (2) integrating non-communicable disease prevention and control into the basic package of care; (3) building managerial capacity; (4) institutionalising community engagement; (5) modernising PHC information systems.
\end{abstract}

\section{INTRODUCTION}

Strengthening systems of primary health care (PHC) is critical to improving health outcomes and overall health systems

\section{Key questions}

What is already known?

- There are large evidence gaps on how primary health care (PHC) should be (re-)organised to integrate chronic disease care with well-established PHC services such as maternal and child health and the treatment of acute infectious diseases.

What are the new findings?

- Strong community-centred approaches and strategies that enhance PHC as the first point of contact with the health system are essential to acceptability of and demand for PHC.

- Community and mid-level health workers can have a positive impact on the quality, coverage and efficiency of PHC services, including in delivering non-communicable disease (NCD) prevention and management.

- Digital decision-support tools can improve quality of care and coverage of services, including to under-served populations, however could be better linked to health information systems.

\section{What do the new findings imply?}

- Future research in the Asia-Pacific region should embrace complexity and focus on strategies for PHC implementation (in collaboration with health systems managers and development partners) to identify enabling factors that support context-specific adaptation and scale-up.

- Practical knowledge and guidance are needed on (1) workforce development, (2) integrating NCD prevention and control into the basic package of care, (3) building managerial capacity, (4) institutionalising community engagement and (5) modernising PHC information systems.

efficiency particularly in contexts where resources are scarce. ${ }^{12}$ In 2018, the Astana Declaration renewed the global commitment 
to PHC made 40 years earlier at Alma-Ata. ${ }^{3}$ Yet, there is still limited knowledge on how to make optimal use of human and other resources to deliver PHC, in other words how to improve the organisation of PHC systems. ${ }^{56}$ In particular, there are large evidence gaps on how PHC should be (re-)organised to integrate chronic disease care with well-established PHC services such as maternal and child health and the treatment of acute infectious diseases. ${ }^{7}$

Core principles of PHC proposed by Starfield-continuity, first-contact access, comprehensiveness, coordination and person-centredness-have been recognised by WHO and re-affirmed by the Astana declaration. ${ }^{389}$ Elements identified as critical to operationalising these principles include an integrated approach to service delivery, a reliable referral system linked to high-quality second-level facilities, a defined package of care, clear structures to engage non-state providers in service delivery, and strong district health systems collecting reliable data and using this to inform planning. ${ }^{1}$ However, less is known about how to design, adapt and deliver these elements in different contexts.

This study reviews and synthesises evidence on models of PHC organisation in low-income and middle-income countries (LMICs) of the Asia Pacific, a region experiencing both rapid change in the health sector and a renewed investment in PHC system strengthening. ${ }^{10}$ Our aim was to understand approaches to and factors influencing the implementation of PHC organisation strategies, in order to help explain their outcomes.

The research presented in this paper was part of a global study on different aspects of PHC in different geographical regions, undertaken by a network of research teams. The broader study maps knowledge gaps in PHC systems across three other domains (governance, quality of care, financing). Our specified focus was organisation and models of PHC in LMICs of the Asia Pacific.

\section{METHODS}

\section{Patient and public involvement}

Patients were not involved in the development of this literature review.

\section{Review question}

The evidence review sought to address the following questions:

1. What is the existing evidence on approaches to the organisation of PHC in the Asia-Pacific region?

2. What evidence is there of the impact or effectiveness of each of the identified approaches? What are the pathways underpinning these outcomes?

3. What are the gaps in knowledge of 'what works' in PHC organisation and financing in LMICs of the AsiaPacific region?

This paper aims to answer the first two questions. A companion paper presents the results in relation to the third question, that is, gaps in evidence on the organisation of PHC service delivery, while a third paper used the same set of questions to guide a review of PHC financing. ${ }^{11} 12$

\section{Review methods}

Online supplementary file 1 presents the conceptual framework we developed to guide the literature search. We searched peer-reviewed publications and grey literature from January 2008 to April 2018; this period was chosen to ensure evidence of intervention effectiveness was recent and therefore relevant to present-day health systems. We then used a narrative approach to summarise findings, generating new insights by systematically comparing, contrasting and extrapolating emerging themes. ${ }^{13}{ }^{14}$ Characteristics of successful interventions and their enabling factors were tabulated.

To complement and help contextualise the review findings, we collated a summary of PHC system characteristics in a subset of LMICs in the Asia Pacific. We selected countries for which a 'Health in Transition' (HiT) country profile was available $(n=14)$ from the Asia Pacific Observatory on Health Systems and Policies, a WHO-hosted partnership; HiTs provide recent, comparable data on PHC systems. ${ }^{15}$ Supplementary information for these countries was collected via a Google search that yielded primary and secondary sources including national/local government websites, journal articles and newspaper articles. Additional sources of indicator data were identified from backwards citation chaining from government websites.

\section{Setting and inclusion/exclusion criteria}

We defined LMICs of the Asia-Pacific region as those countries within the World Bank regions of South Asia and East Asia and Pacific that had an economic classification of low, lower-middle or upper-middle income (as designated in June 2017). ${ }^{16}$ We did not adopt any specific definition of 'primary health care' services but, consistent with the Alma-Ata declaration, our study encompassed facility-based care at lower levels of the health system as well as preventive and promotive services delivered by community health workers (CHWs) and/or formal sector employees. Inclusion and exclusion criteria are found in box 1 . Notably, we searched for intervention studies that, by their nature, often target a specific aspect of the primary care system or a specific set of clinical services. However, our analysis of these studies took a broad, systems perspective consistent with the recognised core principles of PHC.

\section{Search strategy}

Standard database searches were conducted using MEDLINE, Embase, Global Health and Cochrane Database. The search strategy is provided in online supplementary file 2. Database searches were supplemented with a hand search of grey literature from the following websites: WHO-Geneva; WHO-SEARO; WHO-WPRO; World Bank (filtered for East Asia and Pacific, and 


\section{BOX 1 Literature review inclusion and exclusion criteria}

\section{Inclusion criteria}

- Patient/population: No restriction.

- Outcome: Studies evaluating interventions to reorganise PHC delivery with the aim of improving PHC outcomes of quality, coverage, efficiency, responsiveness or equity. *

- Study location: LMICs of the Asia-Pacific region.

- Study design: Randomised controlled trial; clinical trial (non-randomised); cohort study; case-control study; cross-sectional study; pre-post study; comparative study; evaluation study (impact, process, economic); qualitative study; review; systematic review; meta-analysis; government/technical report.

- Publication date: 1 January 2008 to February 2018.

- Publication language: All.

\section{Exclusion criteria}

- Any study that does not meet the stated inclusion criteria.

- Studies with a primary focus on 'Quality, Safety and Performance Management' or 'PHC Policies and Governance' (ie, the two priority areas outside the scope of this report).

- Editorials and letters.

South Asia); Asian Development Bank; Alliance on Health Policy and Systems Research; Asia Pacific Observatory on Health Systems and Policies; Centre for Global Development; Results for Development; Institute for Development Studies (UK); Secretariat for the Pacific Community; Save the Children Fund, International; World Vision, International.

\section{Analysis}

The evidence review and synthesis was conducted in two stages between February and April 2018. In stage 1 , the title and abstract of initial search results were screened and assessed for relevance by three members of the research team (RD, SJ, AP), removing duplicates and publications that did not meet the inclusion criteria. The full text of potentially relevant publications was then retrieved and reviewed for inclusion by two researchers (RD, AP). Reference lists of the final included publications were hand-searched for additional articles relevant to the review, and further relevant articles were identified through consultation with other authors engaged in the global PHC research consortium which produced the studies published in this edition of BMJ Global Health. Figure 1 presents the flow chart of literature selection.

In stage 2, each full-text publication was reviewed to identify key study characteristics (context, geographical scope, research method, study population, disease focus), as well as the PHC system outcomes and inputs specifically addressed by the research. Our first attempt to map literature against categories set out in the conceptual framework found it to be too detailed, with notable overlap between categories and omission of key elements, including outcome measures. We therefore developed a new framework against which to map the results of our literature search with both 'inputs' and 'outcomes' (see online supplementary file 3). Inputs were derived from the conceptual framework, with some re-organisation and re-grouping of categories, while 'outcomes' were identified as those health system attributes underpinning the principles of Universal Health Coverage (UHC) - quality, coverage, efficiency, responsiveness and equity. Four of these five outcome areas are common to both World Bank and WHO frameworks on health systems performance, while the fifth,

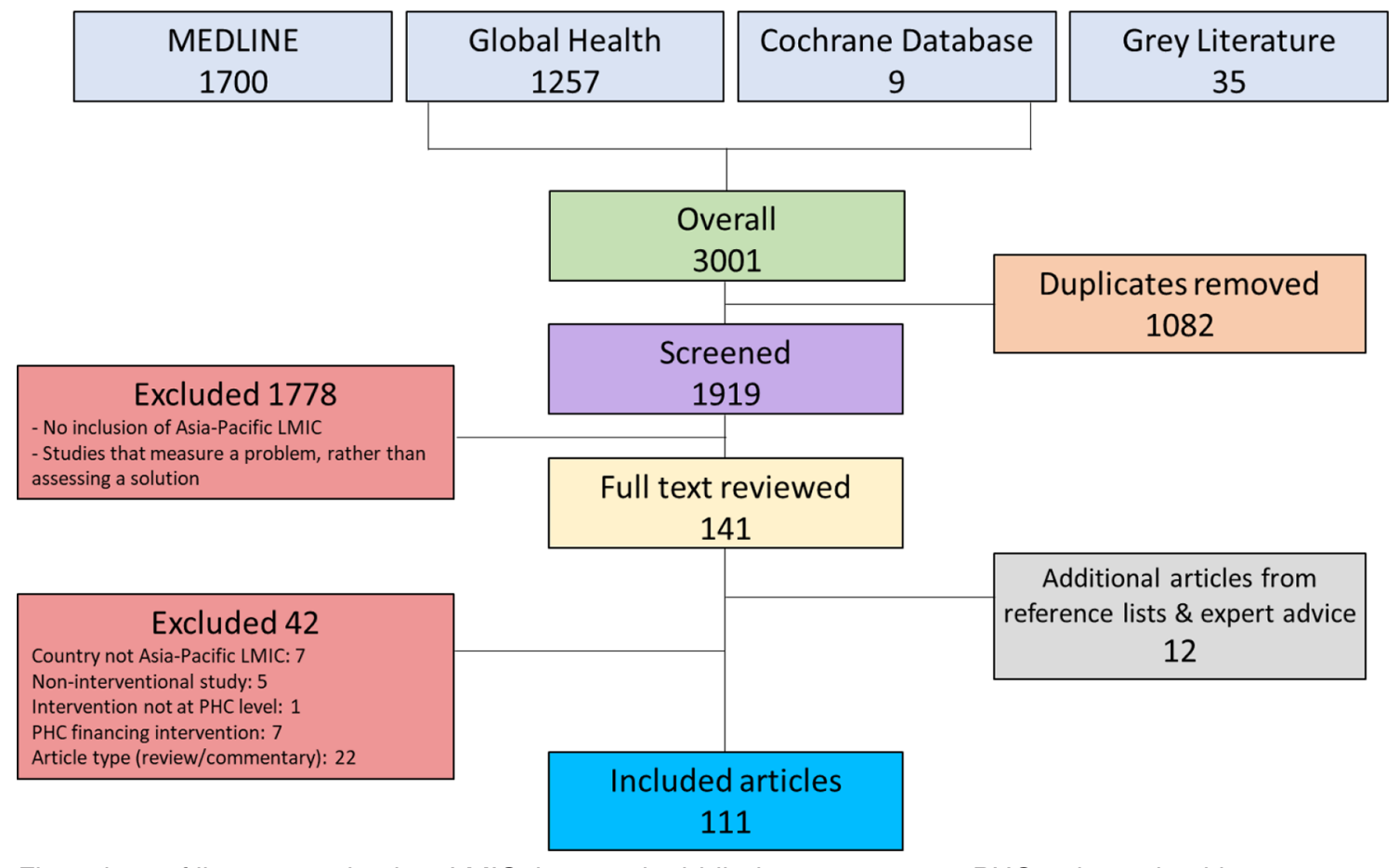

Figure 1 Flow chart of literature selection. LMIC, low- and middle-income country; PHC, primary health care. 
equity, is a focus of health systems analysis in the era of UHC. ${ }^{17-19}$ Other domains commonly referenced as markers of health systems performance are safety and access; we assumed these to be incorporated in definitions of quality and coverage, respectively. We also used the revised framework to guide the identification of major gaps in the literature (see companion paper). ${ }^{11}$

\section{RESULTS \\ PHC system characteristics}

Online supplementary file 4 presents PHC system characteristics in 14 LMICs of the Asia Pacific. It highlights high variation in the level of economic development between countries, resulting in wide variations in health expenditure: from US\$53 per capita in Laos to US $\$ 425$ in China. Despite this, there are many shared organisational features across PHC systems. Notably, every country has a network of village or community health workers, though with various degrees of training and differing remuneration arrangements. Further, in at least five countries, we found no information on whether doctors were available outside the hospital context, for example, practising privately in remote locations. In a further three countries, we only found reports of doctors practising in urban settings or second-level facilities. This suggests non-physician health workers (NPHWs) of varying skill levels including nurses and midwives, and CHWs will continue to have a key role in delivering essential services, even in the better-resourced health systems of middle-income economies.

Just over half the countries reported some kind of gatekeeping policy $(n=8)$ which requires patients to access non-emergency hospital care or specialist services via PHC. ${ }^{20}$ However, we know from other studies that enforcement of gatekeeping arrangements is often difficult in practice, leading to inefficient use of hospital resources. ${ }^{21}$

Eight countries used non-state providers (private or not-for-profit) to deliver PHC in some regions, often in rural areas. This suggests increasing practical experience in government of working in partnership with non-state providers, for example, on how to structure contracts; however, it also points to a level of fragmentation in PHC systems, with a mix of NGOs, state services and private providers all providing services. Nine countries reported some level of fee-for-service at primary care level including seven of the eight countries using non-state providers. However, five of these nine countries also have fee exemptions for poor people in either state-run and or state-contracted services, suggesting that most countries see value in removing financial barriers to access.

\section{Literature synthesis}

A total of 111 articles were included in our synthesis (figure 1) (21 reviews (9 Cochrane, 5 other systematic and 7 non-systematic reviews), 12 grey literature publications and 78 original research). A complete list of included articles is provided in online supplementary file 5. Characteristics of successful interventions and their enabling factors are summarised in tables 1-5; each table relates to one of the five outcome domains identified in our analytical framework (online supplementary file 3). Interventions that targeted multiple outcomes are referenced in more than one table. Although we intended to look at unsuccessful or ineffective interventions, there were too few published articles to reliably provide commentary on this.

\section{Quality of care}

Studies aiming to improve the quality of PHC looked predominantly at how to strengthen PHC workforce capacity and care pathways through interventions such as training and use of decision-support tools and guidelines. Interventions often targeted community or NPHWs and were usually associated with a new service (such as diabetes screening and management). Just two studies recorded reductions in mortality associated with efforts to improve the quality of care, both focused on community health workers in Nepal (table 1). ${ }^{22} 23$

Training was typically short-course and in-service, and tended to focus on specific disease areas such as common mental health conditions, paediatric tuberculosis, childhood pneumonia, neonatal bacterial infections or eye care. ${ }^{22-27}$ In Thailand, community pharmacists were successfully trained to identify and refer people with high-risk diabetes and hypertension, combining a training intervention with an effort to strengthen the care pathway. ${ }^{28}$

Decision support, including standard treatment guidelines, was used in many settings across Asia, but there were no examples from the Pacific. A systematic review of mHealth and eHealth tools including decision-support tools found positive impacts on several quality and access measures such as clinic attendance rates, medication adherence and vaccination uptake. ${ }^{29}$ Noteworthy intervention studies included a large trial in India and China involving community health workers which found an increase in the proportion of patients with cardiovascular disease taking appropriate medication, and a trial of mobile phone-based tools among nurses in India which was associated with improved blood pressure and blood glucose control. ${ }^{30}{ }^{31}$ Facilitators of success for such interventions included (re-) training providers, ensuring guidelines are clear and easy to use, a supportive team structure and a stable medication supply. Further, mobile tools allowed care to be tailored to individual patients and improved access by facilitating outreach and opportunistic screening.

Supportive supervision is an important enabler of quality healthcare. It is characterised by the involvement of informal supervisors and peers as well as line managers, and encompasses teamwork, communication and empowerment of staff alongside oversight of clinical skills. ${ }^{32}$ Three studies, all from India, found 
Table 1 Summary of evidence of interventions to improve PHC quality

\begin{tabular}{|c|c|c|}
\hline What works? & Where? & Why? (enablers of success) \\
\hline \multicolumn{3}{|l|}{ Workforce development } \\
\hline Short-course/in-service training & $\begin{array}{ll} & \text { Goa, India (mental health) } \\
& \text { Bangladesh (paediatric TB) }^{24} \\
& \text { Nepal (neonatal/child health) }\end{array}$ & $\begin{array}{l}\text { Builds/maintains skills and knowledge of } \\
\text { providers } \\
\text { Refresher training supports motivation, } \\
\text { especially of lay workers } \\
\quad \text { Linked to success of task-shifting }\end{array}$ \\
\hline $\begin{array}{l}\text { Peer-mentoring and supportive } \\
\text { supervision }\end{array}$ & $\begin{array}{l}\text { Karnataka, India (maternal and } \\
\text { neonatal health) } \\
\text { Karnataka, India (essential obstetric } \\
\text { care) }^{33} \\
\quad \text { Odisha, India (immunisation) }\end{array}$ & $\begin{array}{l}\text { Dedicated (employed) nurse mentors } \\
\text { Rapport/trust between mentors and PHC } \\
\text { staff } \\
\text { Support visits from trainers for mentors } \\
\text { linked to training } \\
\text { Team-based self-assessment }\end{array}$ \\
\hline
\end{tabular}

\section{Patient management tools}

Decision-support system, for $\longrightarrow$ Telangana, India (hypertension) ${ }^{58}$ example standard treatment guidelines evidence-based care guidelines

\section{- Karnataka, India (maternal and} neonatal health) ${ }^{33}$

- Nepal (neonatal/child health) ${ }^{22}$
- Timor-Leste (eye care medication) ${ }^{27}$

- Rajasthan, India (maternal and neonatal health) ${ }^{100}$

- Malaysia (medical errors) ${ }^{36}$

- Uttar Pradesh, India (maternal and perinatal health) ${ }^{101}$
- Providers (re-)trained in use of decisionsupport tools

- Simple visual aid to support use of care guidelines

- Opportunistic screening by CHWs

- Functional referral system between outreach and facility-based care

- Regular supply of medicines/free medicines

- Supervisory support, coaching: cycle of regular assessment, feedback, training and action

Digital health: mobile phone/ tablet-based decision-support tool
- Himachal Pradesh, India (hypertension, diabetes) $^{31}$

- Haryana, India; Tibet, China (CVD) ${ }^{30}$

- Afghanistan (mental health) ${ }^{76}$

- Andhra Pradesh, India (CVD) ${ }^{102}$
- Ability to tailor patient care based on algorithm

- Easy to follow clinical management guidelines

- Links to virtual consultations (telehealth)

- Enhanced CHW capabilities and motivation

- Clear team structure

- Improved access to screening at home

\section{Outreach and community engagement}

Digital health: text messaging $\quad$ Afghanistan (mental health) ${ }^{76}$

- Malaysia (chronic diseases) ${ }^{103}$

- Community acceptance of technology

- Message content targeted and easy to understand
Participatory problem
identification and solving
- Vietnam (maternal and neonata health) ${ }^{104}$

- Community mobilisation

- Participatory action

- Continuous improvement cycle (plan-do-study-act)

\section{Systems of care}

$\begin{array}{lll}\begin{array}{l}\text { Introduction of CQI systems and } \\ \text { 'structured process change' }\end{array} & \text { Malaysia }^{36} \\ \text { Australia (and Fiji) }^{37} & \text { Training of health staff } & \text { Regular coaching (supervision and } \\ & \text { mentoring) } & \text { Patient education } \\ & & \text { Re-formatted case sheets reduced } \\ & \text { documentation errors } \\ & \text { Presence of local champion }\end{array}$

$\mathrm{CHW}$, community health worker; CQI, continuous quality improvement; CVD, cardiovascular disease; PHC, primary health care.

supportive supervision improved nurse skills in essential obstetric care, maternal and neonatal care and immunisation services. ${ }^{33-35}$ Many other studies also identified supervision, mentoring and/or coachingand its impact on trust and team coherence-as a key element in the success of interventions. 
Table 2 Summary of evidence of interventions to improve PHC coverage

\begin{tabular}{|c|c|c|}
\hline What works? & Where? & Why? (enablers of success) \\
\hline \multicolumn{3}{|l|}{ Service delivery model } \\
\hline $\begin{array}{l}\text { Community-based service } \\
\text { delivery by lay and other non- } \\
\text { physician health workers }\end{array}$ & 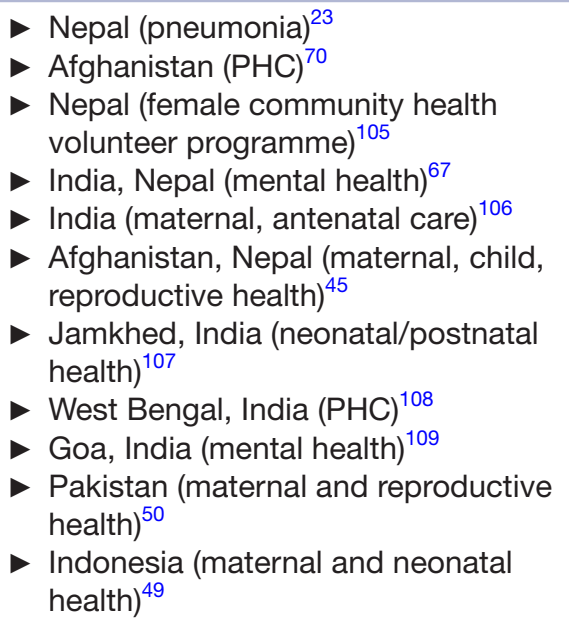 & $\begin{array}{l}\text { Long-term programme development and } \\
\text { maintenance } \\
\text { Strong integration with national health system, } \\
\text { including functional referral system and access } \\
\text { to medicines } \\
\text { Tailored training package (baseline+refresher) } \\
\text { Regular monitoring and supervision } \\
\text { Immediate feedback } \\
\text { Standardised checklists } \\
\text { Community oversight; local ownership } \\
\text { Paired male/female CHWs and peer support } \\
\text { Paintaining CHW motivation through financial } \\
\text { and non-financial incentives (social respect, } \\
\text { community standing) } \\
\text { Cultural acceptance of CHW }\end{array}$ \\
\hline
\end{tabular}

\begin{tabular}{|c|c|c|}
\hline \multicolumn{3}{|c|}{ Outreach and community engagement } \\
\hline $\begin{array}{l}\text { Community-based behaviour } \\
\text { change intervention }\end{array}$ & $\begin{array}{l}\text { American Samoa (diabetes) } \\
\text { - China (CVD, diabetes) } \\
\text { - Pakistan (immunisation) } \\
\text { - Thailand (diabetes prevention) } \\
\text { - American Samoa (prenatal care) } \\
\text { Am }\end{array}$ & $\begin{array}{l}\text { Education sessions with household heads } \\
\text { Reminder services } \\
\text { Cultural connexion between } \mathrm{CHW} \text { and patients } \\
\text { to enhance trust } \\
\text { Participatory design, tailored to needs } \\
\text { Offer of free care for uninsured increased } \\
\text { demand }\end{array}$ \\
\hline
\end{tabular}

$\mathrm{CHW}$, community health worker; CVD, cardiovascular disease; $\mathrm{PHC}$, primary health care.

Only two studies focused on systems of quality improvement. One Malaysian study found a multipronged approach involving training for doctors, patient education, changes to record sheets and use of new decision-support tools to be successful in reducing medical error rates. ${ }^{36}$ The second study reviewed existing approaches to continuous quality improvement (CQI) in rural Australia and considered their applicability for Pacific nations, concluding that CQI is a complex process of change management requiring structured and ongoing support. ${ }^{37}$

\section{Coverage}

Interventions to improve coverage broadly fell into two domains: community outreach programmes and studies of essential facility-based services delivered by NPHWs. The latter encompassed studies by lay, community and/ or mid-level health workers-while these cadres vary significantly in their level of training and capabilities, a common focus of studies was to demonstrate their capacity to deliver interventions effectively (table 2).

Studies of community outreach programmes included behaviour change interventions, particularly for diabetes prevention as well as community education and awareness-raising efforts. ${ }^{26}{ }^{38-44}$ These programmes generally reported improved coverage and in some cases improved clinical outcomes. Success factors included direct contact with the community and targeting of community leaders, tailoring of messages to cultural context, and availability of follow-up or referral services.

The second group of studies on facility-based services delivered by NPHWs were predominantly from South 
Table 3 Summary of evidence of approaches to improve PHC efficiency

\begin{tabular}{|c|c|c|}
\hline What works? & Where? & Why? (enablers of success) \\
\hline \multicolumn{3}{|l|}{ Service delivery model } \\
\hline $\begin{array}{l}\text { Community-based approaches, } \\
\text { task-shifting }\end{array}$ & $\begin{array}{l}\text { Goa, India (mental health) } \\
\text { Thailand (diabetes and hypertension } \\
\text { screening) } \\
\text { - Indonesia, North India (basic package } \\
\text { of care) } \text { ) }^{53112} \\
\text { Pakistan (maternal and reproductive } \\
\text { health) }\end{array}$ & $\begin{array}{l}\text { Proximity of health facility } \\
\text { Focus on cost-effective essential services } \\
\text { (eg, maternal and child health) } \\
\text { Community-based practitioners operate } \\
\text { within an integrated team, supported by } \\
\text { health system }\end{array}$ \\
\hline $\begin{array}{l}\text { Integration of vertical } \\
\text { programmes }\end{array}$ & $\begin{array}{l}\text { Maharashtra, India (HIV prevention) } \\
\text { Orissa, India (leprosy) } \\
\text { - Pakistan (blindness prevention) } \\
\text { - }{ }^{60} \\
\text { Philippines (diabetes prevention and } \\
\text { care) }^{114} \\
\text { Vietnam (mental health) }\end{array}$ & $\begin{array}{l}\text { Sensitisation of staff } \\
\text { Improved co-ordination across programmes } \\
\text { Advocacy with key political and } \\
\text { administrative stakeholders } \\
\text { Adequate resourcing: staff and programme } \\
\text { funds } \\
\text { Use of treatment guidelines }\end{array}$ \\
\hline
\end{tabular}

\section{Health promotion and patient management tools}

\begin{tabular}{|c|c|c|}
\hline Population-based screening & $\begin{array}{l}\text { Bhutan (diabetes and hypertension) } \\
\text { Indonesia (diabetes and } \\
\text { hypertension) }^{56}\end{array}$ & $\begin{array}{l}\text { Universal (Bhutan) or targeted (high-risk } \\
\text { groups }>40 \text { years, Indonesia) more cost- } \\
\text { effective than opportunistic screening } \\
\text { Follow-up treatment follows PEN guidelines }\end{array}$ \\
\hline $\begin{array}{l}\text { Electronic decision-support } \\
\text { tools }\end{array}$ & $\begin{array}{l}\text { Telangana State, India (hypertension } \\
\text { management; physicians) })^{58}\end{array}$ & $\begin{array}{l}\text { More cost-effective than chart-based } \\
\text { support } \\
\text { Link with counselling on lifestyle modification } \\
\text { improves impact }\end{array}$ \\
\hline
\end{tabular}

\section{PHC financing}

Contracting service through non-state providers
- Bangladesh (basic package of care) ${ }^{65}$

- Various (systematic review, basic package of care $)^{64}$

- Pakistan (eye health) ${ }^{60}$

- Punjab, India (PHC) $)^{63}$
- 'Competition' between providers may motivate performance

- Better organisation and management capacity, in part due to autonomy/ independence

- Better systems and capacity to absorb and use budget

- Better infrastructure, equipment, medicines supply

- More staff

- Good community links

- Govt capacity for effective contract management

- Trust between contract managers and providers

- Regular supervisory visits

- Bonus system linked to coverage

- Link to higher-level facilities (also NGO run)

- Combined with insurance model (means patients bypassing PHC have substantially higher out-of-pocket costs)

- Investment in PHC infrastructure (increases willingness to use)

$\mathrm{CHW}$, community health worker; $\mathrm{PHC}$, primary health care.

Asia, especially India. Most reported improved service uptake and/or health outcomes. As with studies related to quality of care, supportive and regular supervision of health workers, strong integration into the health system and good relations with the community were facilitators of success. Two multicountry grey literature reviews found that CHWs, a sub-set of NPHWs, have contributed to the decline of maternal and child mortality rates and helped decrease the burden of TB and malaria. ${ }^{56}$ Similarly, a four-country study (including Nepal and Afghanistan in Asia) found that CHWs have provided effective maternal, neonatal and family planning services. ${ }^{45}$ 
Table 4 Summary of evidence of approaches to improve PHC responsiveness

\begin{tabular}{|c|c|c|}
\hline What works? & Where? & Why? (enablers of success) \\
\hline \multicolumn{3}{|l|}{ Service delivery model } \\
\hline $\begin{array}{l}\text { Use of non-physician health } \\
\text { workers }\end{array}$ & $\begin{array}{l}\text { India and Nepal (mental health) } \\
\text { Thailand (PLHIV ART) } \\
\text { American Samoa (diabetic control) } \\
\text { Af } \\
\text { Afghanistan (basic package of MCH, } \\
\text { disease prevention) }{ }^{70}\end{array}$ & $\begin{array}{l}\text { Positive relationship between CHWs and } \\
\text { community } \\
\text { Convenience of accessing services: home } \\
\text { visits, patient choice of service location } \\
\text { Affordability of services } \\
\text { Availability of medicines } \\
\text { Individualised care plans } \\
\text { Paired male/female CHWs removes gender } \\
\text { barriers to access }\end{array}$ \\
\hline \multicolumn{3}{|l|}{ Community engagement } \\
\hline $\begin{array}{l}\text { Patient/community } \\
\text { engagement }\end{array}$ & $\begin{array}{l}\text { Thailand (diabetes prevention; family } \\
\text { nurses) }{ }^{4172} \\
\text { - Mangalore, India (family folders) }{ }^{71} \\
\text { - Nepal (maternal and child health) }\end{array}$ & $\begin{array}{l}\text { Local ownership: community groups and local } \\
\text { organisations define local problems and are } \\
\text { involved in programme design } \\
\text { - Involvement of village/local leaders } \\
\text { Enhanced healthcare worker trust increases } \\
\text { service utilisation } \\
\text { - Health education sessions and materials in } \\
\text { local language } \\
\text { Partnerships with traditional healers to } \\
\text { integrate 'new' and traditional knowledge }\end{array}$ \\
\hline Family-centred care & $\begin{array}{l}\text { Thailand (family nurses) } \\
\text { Mangalore, India (family folders) }\end{array}$ & $\begin{array}{l}\text { Facilitating change in social context } \\
\text { Strengthens interpersonal/family relationships } \\
\text { Continuity of services }\end{array}$ \\
\hline
\end{tabular}

ART, anti-retroviral therapy; $\mathrm{CHW}$, community health worker; $\mathrm{MCH}$, maternal and child health; PHC, primary health care; PLHIV, persons living with HIV.

Although small-scale and grey literature studies tended to report positive outcomes, Cochrane reviews for immunisation, TB case detection, and maternal and child healthcare-community-level services typically delivered from a PHC facility-had mixed findings. ${ }^{44}{ }^{46-48}$ There was 'low certainty' evidence that providing information to communities, health education at facilities, immunisation cards, and regular outreach could improve immunisation coverage and monetary incentives to parents had no impact on vaccination uptake. ${ }^{46}$ For TB, outreach screening including house-to-house visits could increase case detection, but this had little or no impact on treatment success rates. Further, there was no clear evidence that health promotion (including mass media activities) or training nurses in TB case detection had any impact on reducing $\mathrm{TB}$ prevalence.

Two long-term evaluations of large-scale interventions to improve coverage of essential services through national PHC systems echo these mixed findings. Indonesia's national 'midwife in the village' programme had no lasting impact on birth weight over 10 years, though it did expand the coverage and quality of prenatal care. ${ }^{49}$ In Pakistan, the community-based Lady Health Worker programme was associated with reduced infant and maternal mortality and improved contraceptive prevalence; however, these findings could be attributed to other factors such as rising household incomes. No corresponding improvements in breast feeding, sanitation or community health knowledge were observed. Lack of integration with the health system and high levels of dissatisfaction among health workers due to poor remuneration were identified as factors influencing these outcomes. ${ }^{50}$

\section{Efficiency}

Studies on PHC financing interventions and systems are reviewed in a companion paper; here, we present studies of interventions aiming to improve the efficiency of PHC systems. ${ }^{12}$ The majority of included studies were cost-effectiveness analyses comparing the incremental costs of a new intervention or model of care with the status quo. Studies looked at efficiency gains from task-shifting, that is, using NPHWs to provide an intervention or package of interventions usually delivered by more senior staff; population-based screening; and electronic decision-support tools. ${ }^{24}{ }^{51-57}$ Findings were generally positive, that is, the health worker or service studied represented a cost-effective use of resources. In two cases-treatment of common mental health disorders and population-based screening for non-communicable disease (NCDs) - the interventions were found to be cost-saving. Contributors to success included a team-based approach and good co-ordination between programmes, for example, linking hypertension management in a clinical setting with community-based lifestyle counselling (table 3). ${ }^{245658}$ 
Table 5 Summary of evidence of approaches to improve PHC equity

\begin{tabular}{lll}
\hline What works? & Where? & Why? (enablers of success) \\
\hline Service delivery model & & \\
Use of CHWs (task-shifting) & Myanmar $(\mathrm{PHC})^{75}$ & Community involved in selection of $\mathrm{CHWs}$, \\
& Afghanistan (midwifery) & deployment and retention \\
& & - Commitment from community and families to \\
& & support CHWs \\
& & Baseline and annual refresher training for CHWs \\
& & Established links between clinic-based services \\
& & and mobile teams \\
& & Opportunities for women in rural areas - \\
& & education, work in health delivery
\end{tabular}

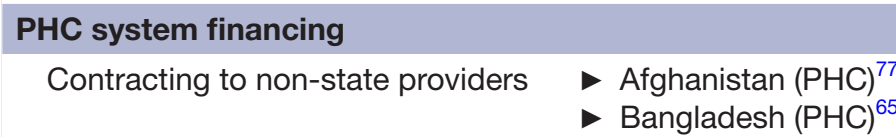

- Bonus system linked to health equity targets

- Health worker education, supervisory visits and supportive supervision; quality of care

- NGO greater flexibility in reallocating fixed budget

- CHWs actively referring patient to NGO-funded tertiary facilities

- Available/improved infrastructure and medicines

- Wider variety of service offered

- Closer ties to community

- Organised outreach services

Community engagement
Community empowerment/ $\quad$ Chattisgarh, India $(\mathrm{PHC})^{78}$
ownership
ownership

- Community-led monitoring, planning and action

- Engagement of community leaders: village health committees, women's leadership

- Data shared with community, consultation on service improvement

- Community mortality data registries available to provide evidence of health inequities

Patient management tools

Digital health: mobile phone/tablet- $\quad$ Afghanistan (mental health) ${ }^{76}$ based decision support tool

- CHWs able to undertake guideline-based screening in remote areas

- Efficient referral links to facility-based services

- Improved access to care through telehealth consultations

- Reduction of stigma in the community

$\mathrm{CHW}$, community health worker; $\mathrm{PHC}$, primary health care.

Several studies examined efficiency gains associated with the integration of new or existing (but managed separately) condition-specific programmes into a broader package of PHC. They also generally reported positive findings. A pilot to incorporate HIV screening into PHC services in Maharashtra, India, increased coverage and saved money. ${ }^{52}$ Also in India, in Orissa, a leprosy programme was integrated into general care without impact on quality or effectiveness. ${ }^{59}$ In Pakistan, blindness prevention was gradually and successfully integrated into routine primary care over an extended period; and in the Philippines, diabetes prevention and management were integrated into the work of existing staff yielding positive clinical outcomes. ${ }^{60}$ Facilitators of integration included strong health managers, provider engagement, and careful planning and co-ordination. Only one study reported negative outcomes, a mental health service integrated into PHC in Vietnam increased coverage for epilepsy and schizophrenia but was unable to expand community-based early intervention and diagnosis for other mental health disorders due to lack of funds and staff. $^{61}$

We found only one empirical study on the cost-effectiveness of gatekeeping in PHC, from China. ${ }^{62}$ The study of a gatekeeping trial reported reduced hospital utilisation, but noted PHC infrastructure enhancements were needed to attract patients. Other studies found that contracting services to non-state providers offered savings by reducing the cost of delivering care mainly due to better administrative, managerial and absorptive capacity among these providers. ${ }^{6063-65}$ The importance of contract management skills in government, and trust 
between government and providers, were highlighted as a critical factors.

\section{Responsiveness}

WHO defines responsiveness as "the ability of the health system to meet the population's legitimate expectations regarding their interaction with the health system" ${ }^{66}$ We found studies relating to key aspects of this definition, that is, patient perceptions of care, and the capacity of the health system to respond to and engage with patients and the community (table 4 ).

Studies on patient views on the quality and acceptability of care provided by lay, community and other NPHW included studies on using lay workers to deliver basic mental healthcare, shifting delivery of anti-retroviral therapy from hospital doctors to community nurses, providing diabetic care through a combined team of nurses and CHWs, and using CHWs to deliver a basic package of maternal and child care and disease prevention services. ${ }^{67-70}$ In Afghanistan, the pairing of male and females CHWs helped reduce gender-based barriers to access. ${ }^{70}$ These strategies report high acceptability rates with patients appreciating the enhanced accessibility of services and the receipt of personalised, patient-centred care. However, a systematic review on barriers and facilitators to lay health worker programmes found that while the community often had high levels of trust in lay workers, they also saw the care delivered by these workers as 'insufficient', particularly when they lacked access to medicines and equipment. ${ }^{47}$ Similarly, one Thai study reported that the community felt nurses based in local facilities delivered lower-quality care while also appreciating the benefit of not having to travel to hospital to receive treatment. ${ }^{68}$

Other studies of responsiveness examined patient engagement in the design of diabetes prevention services, and engaging traditional healers and female community members in developing a maternal and child care intervention. ${ }^{41}{ }^{43}$ Two further studies described working with the community to design and deliver a 'family-centred' PHC service package. In Mangalore, India, family clinical records were reviewed to identify priority needs, determined as malaria and reproductive health, and weekly community-based health education and training for women in infection prevention and control provided. ${ }^{71}$ Over 2 years, the proportion of households using bed nets and practising family planning more than doubled. Similarly, in Thailand, family nurses used regular community meetings to draw out 'social capital' within families and communities, and this resulted in enhanced service utilisation. ${ }^{72}$

\section{Equity}

Only one intervention study was explicitly focused on reducing inequities in health status: a childhood undernutrition programme in China. ${ }^{73}$ The study found that while stunting had declined at aggregate level, inequities in stunting between socioeconomic groups had not reduced. Studies with an implicit equity focus included those concerned with extending services to under-served populations in rural and remote areas and to internally displaced people. ${ }^{53} 7475$ Community engagement in the selection and deployment of CHWs, well-established links with clinic-based services and keeping CHW knowledge up to date all supported the success of such programmes. Equipping CHWs with mobile decision-support tools can further decrease inequities in service coverage by facilitating outreach. ${ }^{76}$ One study found that capacity strengthening for female CHWs in remote areas can itself address gender inequities given employment and skill-building opportunities for women are grossly limited in such areas (table 5). ${ }^{74}$

Contracting services to NGOs and other non-profit providers has also been successful in reducing inequities in service provision. A study from Afghanistan suggests provider autonomy to allocate resources was a key determinant of success along with provision of bonuses linked to increased service uptake among poorer patients. ${ }^{77} \mathrm{Simi}-$ larly, a study from Bangladesh found a contracted NGO to be more effective at reaching the poor with a package of PHC than government providers, likely because it had a better supply of medications, closer community ties and a larger operating budget. ${ }^{65}$

A long-running programme in rural India aimed to empower communities by providing data on health status, access to services and determinants of health, and supporting advocacy for improved services. ${ }^{78}$ A grey literature review of the programme reported sustained levels of community engagement and increased knowledge of health inequities and their causes. However, no evidence was presented on improved equity in access to services or health outcomes. Although an explicit focus of our conceptual framework, we found no studies that aimed to address the political economy or sociopolitical determinants of health policy and health equity.

\section{DISCUSSION}

In this review, we appraised the evidence on strategies to improve PHC organisation in the Asia-Pacific region and identified factors that contributed to success. Although the PHC systems in these countries are highly varied in their structure, workforce and resource base, we identified three common elements of effective PHC organisation, all in line with the Astana declaration, and recommendations for PHC systems strengthening from the 2008 World Health Report on Primary Health Care and the Primary Health Care Performance Initiative. ${ }^{3979}$ First, in line with the principle of person-centredness, strong community-centred approaches that enhance PHC as the first point of contact can enhance the responsiveness of the health system. Community engagement ranges from 'light touch' consultation through to more substantive input as part of a co-design approach. Such approaches increase acceptability for services, and foster community respect and trust 
for PHC systems, in turn reducing demand for hospital-centric care (table 4). Second, reflecting the importance of first-contact access, NPHWs (including lay and CHWs) can have a positive impact on enhancing the quality, coverage and efficiency of PHC services, and there is emerging evidence of their beneficial role in NCD prevention and management. In line with the principle of continuity (and WHO guidance on the role of task-shifting), NPHW models require supportive supervision including encompassing regular supervisory visits, provision of immediate feedback and teambased assessment, a trusting relationship between PHC workers, and senior colleagues and clear pathways to second-level facilities. ${ }^{80}$ Third, when combined with adequate training and support and when well linked to information systems, decision-support tools can improve coverage of services to under-served populations, enhance equity of access and improve quality of care-supporting delivery of co-ordinated and comprehensive care.

There was a dearth of information, however, on how best to operationalise these principles and approaches, or the importance of adequate financing. The majority of original research describes the testing or evaluation of a single intervention or an isolated aspect of service delivery-for example, the use of a particular diagnostic tool, the effectiveness of training to impart a specific capability and the acceptability to the community of a certain change. To an extent, this reflects the limitations of the most commonly used study designs (randomised controlled trial, pre-post, cross-sectional), which dictate that artificial boundaries be drawn around the intervention being studied in order to measure a discernible effect. This approach also characterises PHC as a set of vertical programmesimmunisation, antenatal care, TB control and so onand neglects the health systems complexity which underpins the delivery of these programmes. In some cases, these programmes may be funded and managed separately-for example, when they are financed by global health partnerships-however, in many cases, they are a part of a package of PHC care. Much of the literature we reviewed fails to capture the relationship between the specific programme or intervention studied and the broader package of PHC, or iterative evolution of interventions over time. This limits knowledge generation and, in particular, it makes it hard to identify the enabling factors needed to support successful, context-specific adoption of evidence-based approaches.

To help bridge the gap between the narrowly focused evidence base and generalisable guidance, we propose five areas of further research to support the implementation of PHC systems strengthening strategies which would benefit from further collaborative approaches between health system managers, development agencies and researchers.

\section{Institutionalise and sustain community engagement}

Strong community engagement and participation were integral to early conceptualisations of PHC, including 'health for all' as set out in the Alma-Ata declaration and reiterated in the recent Astana declaration. ${ }^{3} 8182$ Although the studies we reviewed indicate that community engagement is important, processes to enhance engagement were not well explored. Engagement needs to be conceptualised broadly, to encompass the involvement of communities in the planning, design, governance and delivery of services. ${ }^{83}$ Processes that stress the importance of partnership over consultation are required. ${ }^{84}$ This means going beyond one-off exercises to gather information on community needs and priorities-though this is important-to sustained engagement resulting in the transfer of power from health system to communities, allowing communities a role in agenda-setting and actively engaging community members in decision-making. ${ }^{83} 84$ A stronger evidence base would help inform the tailoring of different approaches to community engagement in different contexts, as well as how to monitor and measure the effectiveness of these efforts.

\section{Develop more robust NPHW workforce strategies}

'Non-physicians' are a broad group, encompassing CHWs with just a few weeks' training through to experienced nurses, midwives and other ancillary professions. Strengthening the skills and capacities of this highly varied workforce is nonetheless a common focus of the PHC literature given they are on the frontline of service delivery, often working without supervision. Studies we reviewed suggest training and support provided to NPHWs (including lay and CHWs) is typically one-off, ad hoc and focused on building skills in a particular area. Recent studies in high-income countries suggest efforts to strengthen primary care, including through taskshifting, are not well aligned with workforce development plans, ${ }^{8586}$ which typically prioritise medical and specialist workforce development. It is also likely that many LMICs do not pay sufficient attention to medium-term and longterm needs of their NPHW, or strategically link the development of this workforce to evolving models of PHC and in particular the increasing focus on chronic care. ${ }^{6}$ Comprehensive and differentiated workforce development strategies for NPWHs are needed, which recognise that CHWs will require very different approaches to formal sector workers such as nurses and midwives, but also that all groups require a clear career pathway and remuneration framework that considers both financial and non-financial rewards. In addition to training, these strategies should consider how to build 'team' approaches and strengthen supportive supervision. Researchers can play a key role in providing the evidence to support the implementation of these strategies.

\section{Operationalise an integrated PHC service package}

Increasingly, countries are defining a 'package' of services linked to the achievement of UHC. ${ }^{87}$ Brokering 
agreements on an entire package of services covered under UHC reforms is a complex process that ideally involves the generation of locally relevant evidence of cost-effectiveness. Against this background, interventions delivered through PHC as opposed to hospital setting can be highly cost-effective and acceptable to the community. ${ }^{1798889}$ Until recently, the focus has been on acute care and maternal and child health services, but the importance of integrating NCD prevention and control into the PHC model of care is increasingly recognised. ${ }^{7990}$ Disease-agnostic, integrated service delivery models are therefore a priority. However, we found limited evidence of comprehensive systemsbased approaches to operationalising an integrated package. This means consideration of, for example, staff roles, skills acquisition, supervision and workload, medicines and equipment supply, establishing appropriate care pathways for referral and follow-up, data collection and monitoring, and cost considerations including stimulus funding to transform models of care. Rather, studies focused on a single aspect of the package, such as introducing a new NCD service. A more systems-based approach may be underway in countries, but our review suggests any learnings are not being shared through the academic literature. Researchers have an important role in capturing and disseminating such knowledge.

\section{Build managerial capacity within PHC systems}

Good governance-encompassing accountability to local communities, availability of information on provider performance, robust financial management and procedures to report misuse of resources-is critical to effective service delivery but remains a chronically under-studied element of health systems development and financing. ${ }^{91-93}$ Good health sector management practice is an important aspect of governance. It ensures facilities and the equipment within them are well maintained, medicines are ordered on time and properly stored, outreach activities are integrated and executed effectively, and so on. ${ }^{91}$ Strong managerial capacity is also key to effective contracting of non-state providers to deliver services. Despite this, we found little evidence on how to build managerial systems and capacities to strengthen PHC organisation-or indeed on how 'good management' is defined-suggesting that these functions are neglected at PHC level. Arguably, managerial capacity is most important at PHC level given scarcity of resources and, in remote areas, distance from administrative support in capitals. ${ }^{94}$ More evidence is needed on how to improve capabilities such as planning, budgeting, target setting and monitoring, and these capabilities need to be prioritised in PHC strengthening efforts. Better management will in turn strengthen accountability-as clear target setting and measurement underpins performance monitoring. ${ }^{92}$

\section{Modernise and integrate information systems for PHC}

Information systems can play a key role supporting the organisation and delivery of PHC services, through assessing the health needs of populations, guiding the planning and implementation of health interventions, and facilitating coordination of care. ${ }^{85}$ Yet, in many LMIC contexts, systems for data collection, analysis and dissemination are weak and fragmented, and cannot support even basic monitoring of vital statistics and health trends. ${ }^{96}$ The risk of relying on technological 'fixes' to systemic problems is long recognised. Over 25 years ago, Sandiford et al noted the potential of new means of generating health data to guide PHC reform, but warned this would not be realised without greater attention to how health information is used and by whom. ${ }^{97}$ This observation remains valid today: while we saw promising evidence of the potential of digital health strategies to support PHC systems-for example, through data collection, processing and real-time data analysis-the 'human elements' required to support adoption were often neglected. Most interventions did not recognise the context of relatively weak information systems nor the broader challenges of establishing appropriate data governance standards. Long-standing challenges of ensuring data informs decision-making remain, while new challenges of maintaining confidentiality while promoting transparency and linking data from multiple sources have emerged. ${ }^{98}$ A PHC 'ecosystem' approach is therefore needed.

\section{Limitations}

The majority of studies reviewed were small in scale and limited in scope, making it difficult to generalise findings. Nevertheless, cross-country analysis of country experience is a common and accepted approach to generating cross-cutting lessons, including for PHC. ${ }^{99}$ Although we reviewed many literature sources, it is possible that the search strategy missed some relevant literature. We focused on intervention studies with the objective of gathering evidence of 'what works', and as a result we did not consider narrative reviews or policy analyses which may provide insight on how the broader structure, financing and governance of the health system affects the quality of PHC services. Given the highly dynamic and variable levels of financing of health systems in the region, this will be a particularly important consideration when assessing the suitability of certain interventions. We conducted an extensive search of the grey literature but could not access internal government evaluations of PHC service delivery models given these are not publically available. Due to the high variation in studies and literature sources, we did not conduct a formal appraisal of evidence quality. Finally, the literature remains dominated by evidence from larger countries such as India and China; complex health systems analyses remain relatively rare and there are few systematic reviews or cross-country comparisons to draw out best practices. 


\section{CONCLUSION}

In LMICs of the Asia-Pacific region, the journey towards UHC begins with stronger PHC systems. Even in the most challenging environments, PHC generally represents a cost-effective and feasible approach to delivering critical, life-saving services to the whole population. When basic quality standards are met, $\mathrm{PHC}$ services and their staff often enjoy strong community support, which in turn generates trust in, and support for, the broader health system.

A systematic approach to the review, analysis and synthesis of the PHC literature provides new insights into effective models of PHC organisation which should inform future systems-strengthening efforts. Despite a modest evidence base, we were able to make tentative conclusions on 'what works' in the organisation of PHC and identify gaps where further research is needed, mindful that adaptation to local context is likely to be the key element of success.

\author{
Author affiliations \\ ${ }^{1}$ The George Institute for Global Health, University of New South Wales, Sydney, \\ NSW, Australia \\ ${ }^{2}$ The University of Sydney School of Public Health, Faculty of Medicine and Health, \\ Sydney, NSW, Australia \\ ${ }^{3}$ The George Institute for Global Health, New Delhi, India \\ ${ }^{4}$ The George Institute for Global Health, Beijing, China
}

Acknowledgements Thanks to Felicity Goodyear-Smith and Asaf Bitton for their valuable comments and feedback.

Contributors RD, DP and AP conceived the manuscript. PM led the literature search. RD, AP and SJ screened the literature and RD, AP and PM completed the mapping. RD led the drafting process. DP and AP provided substantial editorial input. DN and MA-A contributed specific sections. CB researched and developed the PHC systems summary (online supplementary file 4) and AP developed the evidence tables (tables 1-5) with input from RD. All authors reviewed drafts of the manuscript, and read and approved the final manuscript.

Funding This publication is based on research funded by Ariadne Labs through Brigham and Women's Hospital, which is the recipient of a Bill \& Melinda Gates Foundation grant.

Disclaimer The findings and conclusions contained within are those of the authors and do not necessarily reflect positions or policies of the Bill \& Melinda Gates Foundation.

Competing interests The authors declare that this research was conducted in the absence of any commercial or financial relationships that could be construed as a potential conflict of interest. SA is the editor in chief of BMJ Global Health, but was not involved in the evaluation or peer-review process of this article.

Patient consent for publication Not required.

Provenance and peer review Not commissioned; externally peer reviewed.

Data availability statement All data relevant to the study are included in the article or uploaded as online supplementary information.

Open access This is an open access article distributed in accordance with the Creative Commons Attribution Non Commercial (CC BY-NC 4.0) license, which permits others to distribute, remix, adapt, build upon this work non-commercially, and license their derivative works on different terms, provided the original work is properly cited, appropriate credit is given, any changes made indicated, and the use is non-commercial. See: http://creativecommons.org/licenses/by-nc/4.0/.

\section{REFERENCES}

1. Rohde J, Cousens S, Chopra M, et al. 30 years after AlmaAta: has primary health care worked in countries? The Lancet 2008;372:950-61.
2. Starfield B. Primary care: an increasingly important contributor to effectiveness, equity, and efficiency of health services. SESPAS report 2012. Gaceta Sanitaria 2012;26(Suppl 1):20-6.

3. Astana Dof. Global conference on primary health care. Astana: World Health Organization and United Nations Childrens' Fund, 2018.

4. Declaration of Alma-Ata International Conference on Primary Health Care. Alma-Ata, USSR 1978.

5. Global Health Workforce Alliance. Mid-level health workers for delivery of essential health services: a global systematic review and country experiences: World Health Organization 2013.

6. Global Health Workforce AllianceWorld Health Organization, Global experience of community health workers for delivery of health related millennium development goals: a systematic review, country case studies, and recommendations for integration into national health systems: World Health Organization 2010

7. Beaglehole R, Epping-Jordan J, Patel V, et al. Improving the prevention and management of chronic disease in low-income and middle-income countries: a priority for primary health care. The Lancet 2008;372:940-9.

8. Starfield B. Is primary care essential? The Lancet 1994;344:1129-33.

9. World Health Organization. Primary health care: now more than ever. Geneva: World Health Report, 2008: 52-3.

10. Western Pacific regional strategy for health systems based on the values of primary health care. Manila: Western Pacific Regional Office of World Health Organization 2010.

11. Palagyi A, Dodd R, Jan S, et al. Organisation of primary health care: developing a prioritised research agenda in the Asia-Pacific region. BMJ Global Health 2018. [Epub ahead of print: 27 Jun 2019]. In press.

12. Blake Angell RD, Palagyi A, Gadsden T, et al. Primary health care financing interventions: a systematic review and development of a stakeholder-driven research agenda for the Asia-Pacific region 2018.

13. Mays N, Pope C, Popay J. Systematically reviewing qualitative and quantitative evidence to inform management and policy-making in the health field. J Health Serv Res Policy 2005;10(1_suppl):6-20.

14. Jones K. Mission drift in qualitative research, or moving toward a systematic review of qualitative studies, moving back to a more systematic narrative review. The Qualitative Report 2004;9:94-111.

15 Asia Pacific Observatory on Health Systems and Policies, 2019. Available: http://www.searo.who.int/entity/asia_pacific_observatory

16. The World Bank. World Bank Country and Lending Groups, 2017. Available: https://datahelpdesk.worldbank.org/knowledgebase/ articles/906519-world-bank-country-and-lending-groups

17. Berman P, Bitran R. Health systems analysis for better health systems strengthening health, nutrition and population discussion paper. Washington DC: World Bank, 2011.

18. World Health Organization. Everybody's business: strengthening health systems to improve health outcomes: WHO's framework for action. Geneva: World Health Organization, 2007.

19. Gwatkin DR, Ergo A. Universal health coverage: friend or foe of health equity? The Lancet 2011;377:2160-1.

20. Scott A, Jan S. Primary care (chapter 20). In: Smith P, Glied S, eds. Oxford handbook of health economics. Oxford: Oxford University Press, 2011

21. Xu J, Mills A. Challenges for gatekeeping: a qualitative systems analysis of a pilot in rural China. Int J Equity Health 2017;16:106.

22. Khanal S, Sharma J, GC VS, et al. Community health workers can identify and manage possible infections in neonates and young infants: MINI-a model from Nepal. J Health Popul Nutr 2011;29:255-64.

23. Dawson $\mathrm{P}$, Pradhan $\mathrm{Y}$, Houston $\mathrm{R}$, et al. From research to national expansion: 20 years' experience of community-based management of childhood pneumonia in Nepal. Bull World Health Organ 2008:86:339-43.

24. Buttorff $\mathrm{C}$, Hock R, Weiss $\mathrm{H}$, et al. Economic evaluation of a taskshifting intervention for common mental disorders in India. Bull World Health Organ 2012;90:813-21.

25. van Ginneken N, Tharyan P, Lewin S, et al. Non-specialist health worker interventions for the care of mental, neurological and substance-abuse disorders in low- and middle-income countries. Cochrane Database Syst Rev 2013;57.

26. Islam Z, Sanin KI, Ahmed T, Ziaul I, Tahmeed A. Improving case detection of tuberculosis among children in Bangladesh: lessons learned through an implementation research. BMC Public Health 2017;17:131.

27. Higuchi M, Okumura J, Aoyama A, et al. Use of medicines and adherence to standard treatment guidelines in rural community 
health centers, Timor-Leste. Asia Pac J Public Health 2015;27:NP2 498-NP2511.

28. Sookaneknun P, Saramunee K, Rattarom R, et al. Economic analysis of the diabetes and hypertension screening collaboration between community pharmacies and a Thai government primary care unit. Prim Care Diabetes 2010;4:155-64.

29. Marcolino MS, Oliveira JAQ, D'Agostino M, et al. The impact of mhealth interventions: systematic review of systematic reviews. JMIR mHealth and uHealth 2018;6:e23.

30. Tian M, Ajay VS, Dunzhu D, et al. A cluster-randomized, controlled trial of a simplified multifaceted management program for individuals at high cardiovascular risk (SimCard trial) in rural Tibet, China, and Haryana, India. Circulation 2015;132:815-24.

31. Ajay VS, Jindal D, Roy A, et al. Development of a smartphoneenabled hypertension and diabetes mellitus management package to facilitate evidence-based care delivery in primary healthcare facilities in India: the mPower Heart Project. J Am Heart Assoc 2016;5:21.

32. Marquez L. Making supervision supportive and sustainable: new approaches to old problems (MAQ paper no. 4). Maximizing access and quality initiative. Washington, D.C.: United States Agency for International Development (USAID) 2002.

33. Bradley J, Jayanna K, Shaw S, et al. Improving the knowledge of labour and delivery nurses in India: a randomized controlled trial of mentoring and case sheets in primary care centres. BMC Health Serv Res 2017;17:14.

34. Fischer EA, Jayana K, Cunningham T, et al. Nurse mentors to advance quality improvement in primary health centers: lessons from a pilot program in Northern Karnataka, India. Glob Health Sci Pract 2015;3:660-75.

35. Panda B, Pati S, Nallala S, et al. How supportive supervision influences immunization session site practices: a quasiexperimental study in Odisha, India. Glob Health Action 2015;8:25772.

36. Khoo EM, Sararaks S, Lee WK, et al. Reducing medical errors in primary care using a pragmatic complex intervention. Asia Pacific Journal of Public Health 2015;27:670-7.

37. Gardner K, Bailie R, Si D, et al. Reorienting primary health care for addressing chronic conditions in remote Australia and the South Pacific: review of evidence and lessons from an innovative quality improvement process. Aust J Rural Health 2011;19:111-7.

38. Hamid S, Dunsiger S, Seiden A, et al. Impact of a diabetes control and management intervention on health care utilization in American Samoa. Chronic IIIn 2014;10:122-34.

39. Lin A, Zhang G, Liu Z, et al. Community-based lifestyle intervention for reducing blood pressure and glucose among middle-aged and older adults in China: a pilot study. Int J Environ Res Public Health 2014;11:11645-63.

40. Ali Z, Pongpanich S, Kumar R. Effectiveness of community service model for increasing routine immunization coverage at primary healthcare facilities in a rural district of Pakistan: a quasiexperimental study. J Ayub Med Coll Abbottabad 2015;27:853-7.

41. Oba N, McCaffrey R, Choonhapran P, et al. Development of a community participation program for diabetes mellitus prevention in a primary care unit, Thailand. Nurs Health Sci 2011;13:no-9.

42. Nair MK, Russell PS. Adolescent health care in India: progressive, regressive or at the cross-roads?. Indian J Pediatr 2012;79(Suppl 1):S1-5.

43. Morrison J, Osrin D, Shrestha B, et al. How did formative research inform the development of a women's group intervention in rural Nepal? J Perinatol 2008;28:S14-S22.

44. Mhimbira FA, Cuevas LE, Dacombe R, et al. Interventions to increase tuberculosis case detection at primary healthcare or community-level services. Cochrane Database Syst Rev 2017;382.

45. Haver J, Brieger W, Zoungrana J, et al. Experiences engaging community health workers to provide maternal and newborn health services: implementation of four programs. Int J Gynaecol Obstet 2015;130 Suppl 2:S32-S39.

46. Oyo-Ita A, Wiysonge CS, Oringanje C, et al. Interventions for improving coverage of childhood immunisation in low- and middleincome countries. Cochrane Database Syst Rev 2016;9 Suppl 1.

47. Glenton C, Colvin CJ, Carlsen B, et al. Barriers and facilitators to the implementation of lay health worker programmes to improve access to maternal and child health: qualitative evidence synthesis. Cochrane Database Syst Rev 2013;(10):Cd010414.

48. Lewin S, Munabi-Babigumira S, Glenton C, et al. Lay health workers in primary and community health care for maternal and child health and the management of infectious diseases. Cochrane Database Syst Rev 2010;94:Cd004015.

49. Triyana M. The effects of Indonesia's 'Midwife in the Village' programme 10 years post-launch. Popul Stud 2016;70:365-76.
50. Wazir MS, Shaikh BT, Ahmed A. National program for family planning and primary health care Pakistan: a SWOT analysis. Reprod Health 2013;10:60.

51. Sookaneknun P, Suttajit S, Ploylearmsang C, et al. Health promotion integrated into a Thai PharmD curriculum to improve pharmacy practice skills. Am J Pharm Educ 2009;73:78.

52. Bindoria SV, Devkar R, Gupta I, et al. Development and pilot testing of HIV screening program integration within public/primary health centers providing antenatal care services in Maharashtra, India. BMC Res Notes 2014:7:177.

53. McPake B, Edoka I, Witter S, et al. Cost-effectiveness of community-based practitioner programmes in Ethiopia, Indonesia and Kenya. Bull World Health Organ 2015;93:631-9.

54. Prinja S, Gupta A, Verma R, et al. Cost of delivering health care services in public sector primary and community health centres in North India. PLoS One 2016;11:e0160986.

55. Dukpa W, Teerawattananon $\mathrm{Y}$, Rattanavipapong W, et al. Is diabetes and hypertension screening worthwhile in resource-limited settings? An economic evaluation based on a pilot of a Package of Essential Non-communicable disease interventions in Bhutan. Health Policy Plan 2015;30:1032-43.

56. Rattanavipapong W, Luz ACG, Kumluang S, et al. One step back, two steps forward: an economic evaluation of the PEN program in Indonesia. Health Systems \& Reform 2016;2:84-98.

57. Anchala R, Pant H, Prabhakaran D, et al. Decision support system (DSS) for prevention of cardiovascular disease (CVD) among hypertensive (HTN) patients in Andhra Pradesh, India-a cluster randomised community intervention trial. BMC Public Health 2012;12:393.

58. Anchala R, Kaptoge S, Pant $\mathrm{H}$, et al. Evaluation of effectiveness and cost-effectiveness of a clinical decision support system in managing hypertension in resource constrained primary health care settings: results from a cluster randomized trial. J Am Heart Assoc 2015; 4:e001213.

59. Siddiqui MR, Velidi NR, Pati S, et al. Integration of leprosy elimination into primary health care in Orissa, India. PLoS One 2009;4:e8351.10.1371/journal.pone.0008351

60. Khan AA, Khan NU, Bile KM, et al. Creating synergies for health systems strengthening through partnerships in Pakistan-a case study of the national eye health programme. East Mediterr Health $J$ 2010;16 Suppl:61-8.

61. CH N, Than PT, CD L, et al. The national community mental health care project in Vietnam: a review for future guidance. Australas 2011:19:143-50.

62. Li W, Gan Y, Dong X, et al. Gatekeeping and the utilization of community health services in Shenzhen, China: a cross-sectional study. Medicine 2017;96:e7719.

63. Loevinsohn B, Haq lul, Couffinhal A, et al. Contracting-in management to strengthen publicly financed primary health services - the experience of Punjab, Pakistan. Health Policy 2009;91:17-23.

64. Nachtnebel M, O'Mahony A, Pillai N, et al. Effectively engaging the private sector through vouchers and contracting - a case for analysing health governance and context. Soc Sci Med 2015;145:193-200.

65. Heard A, Nath DK, Loevinsohn B. Contracting urban primary healthcare services in Bangladesh-effect on use, efficiency, equity and quality of care. Trop Med Int Health 2013;18:861-70.

66. World Health Organization. Health Systems Responsiveness. Available: https://www.who.int/responsiveness/en/

67. Mendenhall E, De Silva MJ, Hanlon C, et al. Acceptability and feasibility of using non-specialist health workers to deliver mental health care: stakeholder perceptions from the PRIME district sites in Ethiopia, India, Nepal, South Africa, and Uganda. Soc Sci Med 2014:118:33-42.

68. Aung MN, Moolphate S, Kitajima T, et al. Satisfaction of HIV patients with task-shifted primary care service versus routine hospital service in northern Thailand. J Infect Dev Ctries 2015;9:1360-6.

69. DePue JD, Dunsiger S, Seiden AD, et al. Nurse-community health worker team improves diabetes care in American Samoa: results of a randomized controlled trial. Diabetes Care 2013;36:1947-53.

70. Edward A, Branchini C, Aitken I, et al. Toward universal coverage in Afghanistan: a multi-stakeholder assessment of capacity investments in the community health worker system. Soc Sci Med 2015:145:173-83

71. Shivalli S, Majra JP, Akshaya KM, et al. Family centered approach in primary health care: experience from an urban area of Mangalore, India. The Scientific World Journal 2015;2015:1-8.

72. Jongudomkarn D, Macduff C. Development of a family nursing model for prevention of cancer and other noncommunicable 
diseases through an appreciative inquiry. Asian Pac $J$ Cancer Prev 2015;15:10367-74.

73. Pei L, Wang D, Ren L, et al. Evaluation of the Rural Primary Health Care project on undernutrition equity among children in rural Western China. Health Policy Plan 2013;28:429-34.

74. Mohmand KA. Community Midwifery Education Program in Afghanistan. Health, Nutrition, and Population (HNP) discussion paper. Washington, DC: World Bank, 2013.

75. Low S, Tun KT, Mhote NPP, et al. Human resources for health: task shifting to promote basic health service delivery among internally displaced people in ethnic health program service areas in eastern Burma/Myanmar. Glob Health Action 2014;7:24937.

76. Khoja S, Scott R, Husyin N, et al. Impact of simple conventional and Telehealth solutions on improving mental health in Afghanistan. J Telemed Telecare 2016;22:495-8.

77. Alonge O, Gupta S, Engineer C, et al. Assessing the pro-poor effect of different contracting schemes for health services on health facilities in rural Afghanistan. Health Policy Plan 2015;30:1229-42.

78. Garg S. Chhattisgarh Swasth Panchayat Yojana: convergent community action for health and its determinants in rural India. Singapore: Springer, 2017.

79. Bitton A, Ratcliffe HL, Veillard JH, et al. Primary health care as a foundation for strengthening health systems in low- and middleincome countries. J Gen Intern Med 2017;32:566-71.

80. World Health Organization. Task shifting : rational redistribution of tasks among health workforce teams: global recommendations and guidelines. Geneva: WHO, 2008.

81. Cueto $M$. The origins of primary health care and selective primary health care. Am J Public Health 2004:94:1864-74.

82. Magnussen L, Ehiri J, Jolly P. Comprehensive versus selective primary health care: lessons for global health policy. Health Aff 2004;23:167-76.

83. O'Mara-Eves A, Brunton G, McDaid D, et al. Public Health Research. Community engagement to reduce inequalities in health: a systematic review, meta-analysis and economic analysis. Southampton UK: NIHR Journals Library, 2013.

84. Kilpatrick S. Multi-level rural community engagement in health. Aust J Rural Health 2009;17:39-44.

85. Maier CB, Batenburg R, Birch S, et al. Health workforce planning: which countries include nurse practitioners and physician assistants and to what effect? Health Policy 2018;122:1085-92.

86. Kuhlmann E, Groenewegen PP, Bond C, et al. Primary care workforce development in Europe: an overview of health system responses and stakeholder views. Health Policy 2018;122:1055-62.

87. Glassman A, Giedion U, Smith PC, et al. What's out: designing benefits for universal health coverage. Washington DC: Center for Global Development, 2017.

88. WHO/World Bank. Tracking universal health coverage: 2017 global monitoring report. World Health Organization and International Bank for Reconstruction and Development/The World Bank 2017.

89. Jamison DT, Summers LH, Alleyne G, et al. Global health 2035: a world converging within a generation. The Lancet 2013:382:1898-955.

90. Nugent R, Bertram MY, Jan S, et al. Investing in non-communicable disease prevention and management to advance the Sustainable Development Goals. The Lancet 2018;391:2029-35.

91. Fryatt $R$, Bennett $S$, Soucat $A$. Health sector governance: should we be investing more? BMJ Glob Health 2017;2:e000343.

92. Alliance H. Neglected health systems research: governance and accountability. Research issues. Geneva: Alliance For Health Systems and Policy Research, 2008.

93. Phua KH. Governance issues in health financing. Elsevier: Reference Module in Biomedical Sciences, 2018.

94. Olivier de Sardan J-P. Practical norms: informal regulations within public bureaucracies (in Africa and beyond). In: De Herdt T, Olivier de Sardan J-P, eds. Real governance and practical norms in subSaharan Africa the game of the rules. Oxon, UK: Routledge, 2015.

95. Azubuike MC, Ehiri JE. Health information systems in developing countries: benefits, problems, and prospects. J R Soc Promot Health 1999;119:180-4.
96. World Health Organization. Framework and standards for country health information systems. 2nd Ediiton. Geneva, 2012.

97. Sandiford P, Annett H, Cibulskis R. What can information systems do for primary health care? An international perspective. Soc Sci Med 1992;34:1077-87.

98. Hripcsak G, Bloomrosen M, FlatelyBrennan P, et al. Health data use, stewardship, and governance: ongoing gaps and challenges: a report from AMIA's 2012 Health Policy Meeting. J Am Med Inform Assoc 2014;21:204-11.

99. Alliance for Health Policy and Systems Research. Primary Health Care Systems (PRIMASYS) case studies: World Health Organization. Available: https://www.who.int/alliance-hpsr/projects/ primasys/en/

100. lyengar K, Jain M, Thomas S, et al. Adherence to evidence based care practices for childbirth before and after a quality improvement intervention in health facilities of Rajasthan, India. BMC Pregnancy Childbirth 2014;14:270.

101. Semrau KEA, Hirschhorn LR, Marx Delaney M, et al. Outcomes of a coaching-based WHO safe childbirth checklist program in India. $N$ Engl J Med 2017;377:2313-24.

102. Praveen D, Patel A, Raghu A, et al. SMARTHealth India: development and field evaluation of a mobile clinical decision support system for cardiovascular diseases in rural India. JMIR Mhealth Uhealth 2014;2:e54.

103. Liew S-M, Tong SF, Lee VKM, Mun Lee VK, et al. Text messaging reminders to reduce non-attendance in chronic disease follow-up: a clinical trial. Br J Gen Pract 2009;59:916-20.

104. Persson Lars Åke, Nga NT, Målqvist M, et al. Effect of facilitation of local maternal-and-newborn stakeholder groups on neonatal mortality: cluster-randomized controlled trial. PLOS Med 2013;10:e1001445

105. Glenton C, Scheel IB, Pradhan S, et al. The female community health volunteer programme in Nepal: decision makers' perceptions of volunteerism, payment and other incentives. Soc Sci Med 2010;70:1920-7.10.1016/j.socscimed.2010.02.034

106. Vellakkal S, Gupta A, Khan Z, et al. Has India's national rural health mission reduced inequities in maternal health services? A pre-post repeated cross-sectional study. Health Policy Plan 2017;32:79-90.10.1093/heapol/czw100

107. Mann V, Eble A, Frost C, et al. Retrospective comparative evaluation of the lasting impact of a community-based primary health care programme on under- 5 mortality in villages around Jamkhed, India. Bull World Health Organ 2010;88:727-36.

108. Das J, Chowdhury A, Hussam R, et al. The impact of training informal health care providers in India: a randomized controlled trial. Science 2016;354:07.

109. Shinde S, Andrew G, Bangash O, et al. The impact of a lay counselor led collaborative care intervention for common mental disorders in public and private primary care: a qualitative evaluation nested in the MANAS trial in Goa, India. Soc Sci Med 2013;88:48-55

110. Hawley NL, Brown C, Nu'usolia O, et al. Barriers to adequate prenatal care utilization in American Samoa. Matern Child Health $J$ 2014; 18:2284-92.

111. Nair MKC, Chacko DS, Indira MS, et al. A primary care approach for adolescent care and counseling services. Indian J Pediatr 2012;79:79-83

112. Prinja S, Jeet G, Verma R, et al. Economic analysis of delivering primary health care services through community health workers in 3 North Indian states. PLoS One 2014:9:e91781.

113. Siddiqui MR, Velidi NR, Pati S, et al. Integration of leprosy elimination into primary health care in Orissa, India. PLoS One 2009;4:e8351.

114. Ku GMV, Kegels G. Integrating chronic care with primary care activities: enriching healthcare staff knowledge and skills and improving glycemic control of a cohort of people with diabetes through the First Line Diabetes Care Project in the Philippines. Glob Health Action 2014;7:25286. 